
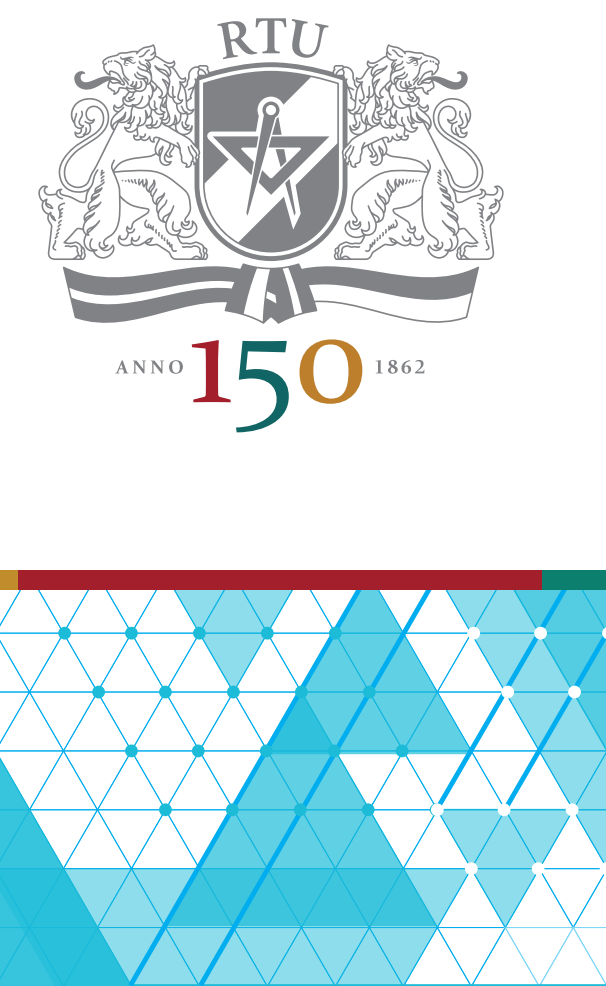

11-12 October 2012, Riga

Riga Technical University 53rd International Scientific Conference

Dedicated to the $150^{\text {th }}$ Anniversary and The 1 st Congress of World Engineers and Riga Polytechnical Institute / RTU Alumni

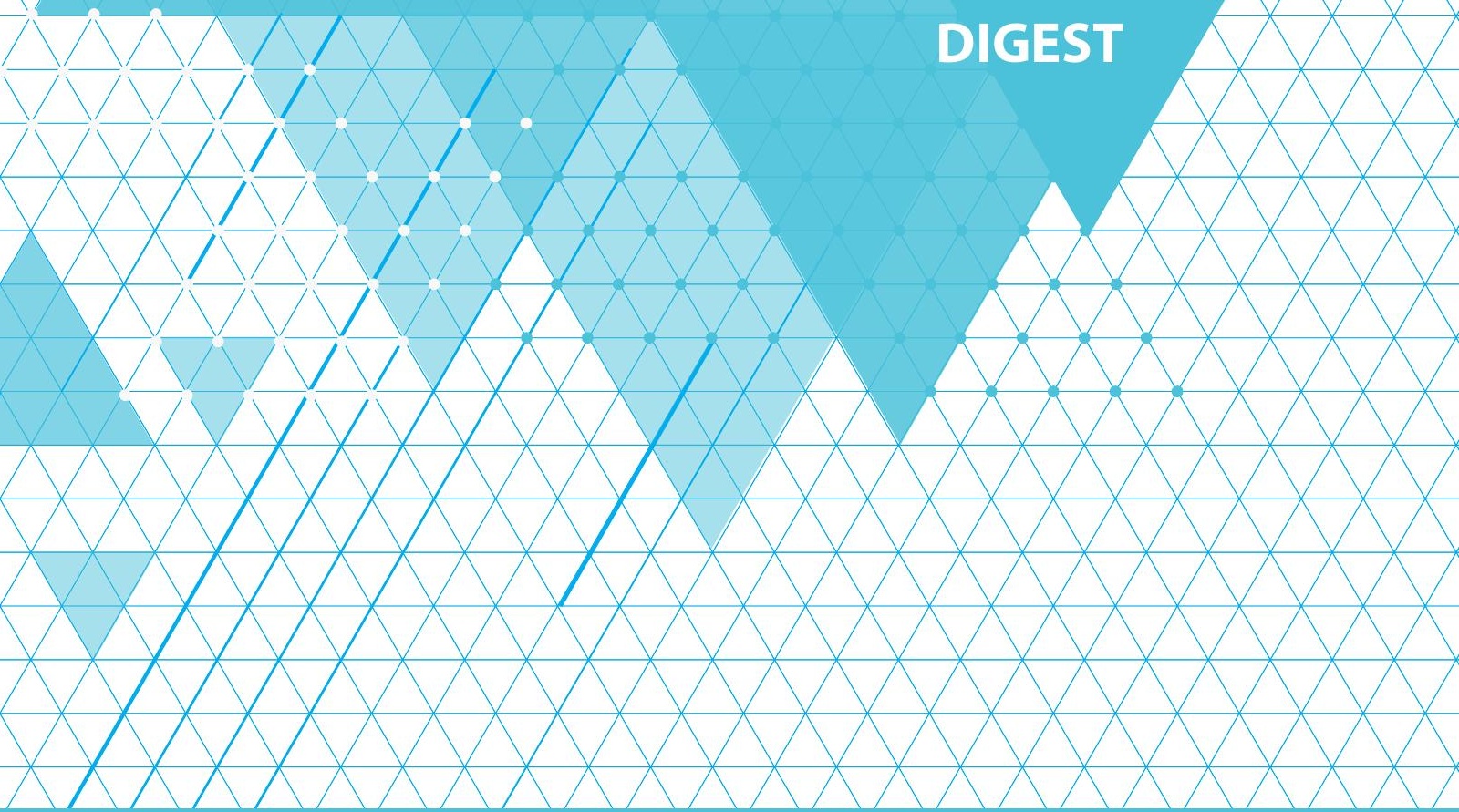




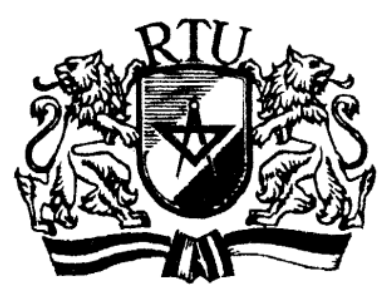

\section{RIGA TECHINICAL UNIVERSITY $53^{\text {rd }}$ INTERNATIONAL SCIENTIFIC CONFERENCE DEDICATED TO THE $150^{\text {th }}$ ANNIVERSARY AND THE $1^{\text {st }}$ CONGRESS OF WORLD ENGINEERS AND RIGA POLYTECHINICAL INSTITUTE / RTU ALUMINI}

11-12 October 2012

Rīga, Latvija 
Riga Technical University $53^{\text {rd }}$ International Scientific Conference dedicated to the $150^{\text {th }}$ anniversary and The $1^{\text {st }}$ Congress of World Engineers and Riga Polytechnical Institute / RTU Alumni

\title{
Time Dependent Deterioration of the X-ray Dental Diagnostic Equipment
}

\author{
Yuri Dekhtyar (Riga Technical University), Alena Kamenetskikh (Ural State University of Railway Transport), \\ Maksims Polakovs (University of Latvia) and Maksims Sneiders (Riga Technical University)
}

Keywords - dental x-ray equipment, time, degradation.

\section{INTRODUCTION}

Statistics presented by NMS GRUPA Ltd. demonstrates that the Trophy ELITYS (25\%) (further in text-ELITYS) is the most popular dental X-ray with high frequency and the Trophy IRIX 70 (13\%) (further in text - IRIX 70) - with half-period generators in Latvia.

Time dependent degradation of $\mathrm{x}$-ray machines gives a strong impact on quality of diagnostics. However, there are no data on time dependent degradation.

The goal of the study was to explore time dependent behavior of dental x-rays ELITYS and IRIX 70 dose providing parameters such as:

- X-ray tube voltage [kV]. Quality of this parameter has an influence on a spectrum, image quality, and an absorbed dose.

- X-ray exposure time [ms] - influences the absorbed dose.

- X-ray tube output [mGy/mAs] influences the absorbed dose.

- Air KERMA [mGy] - influences the absorbed dose [1].

\section{MATERIALS AND METHODS}

Selection of the parameters has been done on the demands by the Republic of Latvia Cabinet of Ministers No. 97 of March 5, 2002 "Regulations on protection against ionizing radiation in medical exposure" [2].

Statistical processing of the collected data (arithmetic mean, experimental standard deviation) has been determined in accordance with EAL Publication EA-4/02 [3].

The correlation of the approximation of the $\mathrm{x}$-ray machine parameters with respect to time has been verified by linear and polynomial (2nd and 3rd order) functions. The "least squares" method has been applied to confirm the best approximation.

\section{RESULTS}

The results are presented in Figure 3.1.High frequency generator type - ELITYS

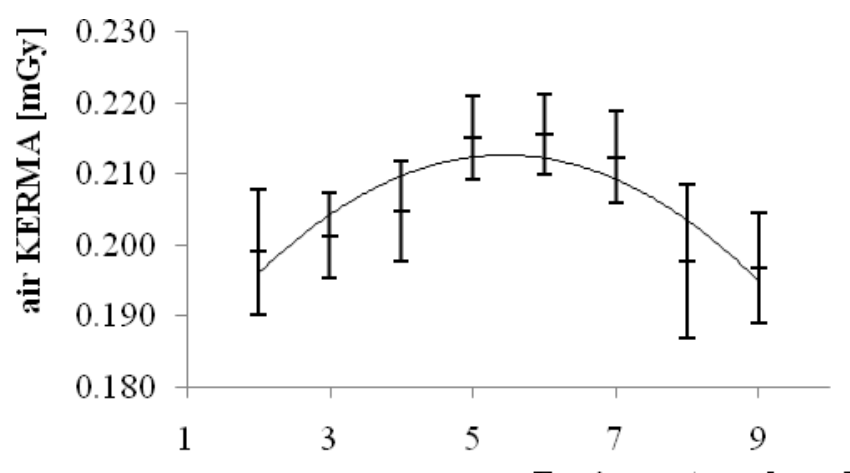

Equipment age [y ear]

Fig. 1. The influence of the age of equipment on air KERMA
Air KERMA follows the polynomial 2nd order correlation with a parameter maximum on equipment's 5-6 year age, during first 4 years increases by $7.4 \%$. During next 4 years results decreases by $8.8 \%$.

A. Half-period generator type - IRIX 70

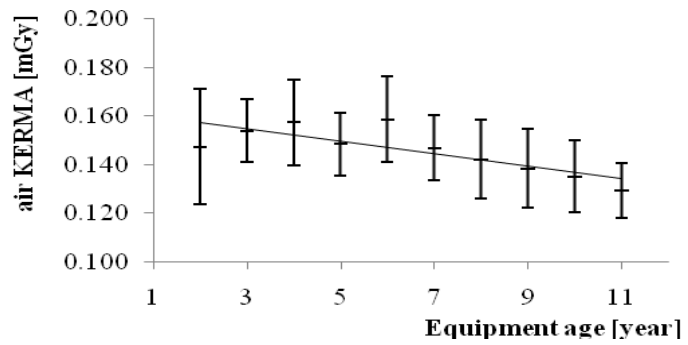

Fig. 2. The influence of the age of equipment on air KERMA

The linear approximation has been confirmed for air KERMA. Air KERMA follows the linear correlation and during 10 years decreases by $14.3 \%$.

\section{CONCLUSIONS}

1. Degradation of dose characterizing parameters were explored for dental x-ray ELITYS with high frequency generator type for over 8 year of the equipment age.

2. Deviation of the parameters comparing first and last year (the 8 year of equipment exploitation) of studied equipment is shown in Table 1.

TABLE 1. DEVIATION OF THE PARAMETERS

\begin{tabular}{lc}
\hline Dose characterizing parameters & Deviation, \% \\
\hline x-ray tube voltage $[\mathrm{kV}]$ & -1.1 \\
X-ray exposure time $[\mathrm{ms}]$ & +0.4 \\
air KERMA [mGy] & -1.0 \\
x-ray tube output $[\mathrm{mGy} / \mathrm{mAs}]$ & -2.0 \\
\hline
\end{tabular}

3. Degradation of dose characterizing parameters were explored for dental x-ray IRIX 70 with half-period generator type for 10 year of the equipment exploitation (Table 4.2).

TABLE 2 DEVIATION OF THE PARAMETERS

\begin{tabular}{lc}
\hline Dose characterizing parameters & Deviation, \% \\
\hline X-ray tube voltage $[\mathrm{kV}]$ & -1.2 \\
X-ray exposure time $[\mathrm{ms}]$ & +0.5 \\
air KERMA [mGy] & -12.3 \\
X-ray tube output [mGy/mAs] & -14.3 \\
\hline
\end{tabular}

\section{REFERENCES}

[1] Dehtjars Ju., Emzins Dz., Jurkevics Ar., et al. (2006) Radiation safety for radiology technologists. In Latvian: Radiācijas drošība radiologu asistentiem. RTU 336.

[2] Demands by the Cabinet of Ministers No. 97 of March 5, 2002 "Regulations on protection against ionizing radiation in medical exposure" at http://www.likumi.lv/.

[3] EAL Publication EA-4/02 at http://www.european-accreditation.org/. 